\title{
Predictors of mortality in COPD exacerbation cases presenting to the respiratory intensive care unit
}

Yang Cao ${ }^{1,2,3 \dagger}$, Zhenzhen Xing ${ }^{1,2,3 \dagger}$, Huanyu Long ${ }^{1,2,3 \dagger}$, Yilin Huang ${ }^{1,2,3 \dagger}$, Ping Zeng ${ }^{2,3,5}$, Jean-Paul Janssens ${ }^{6}$ and Yanfei Guo 1,2,3,4*

\begin{abstract}
Background: Studies report high in-hospital mortality of acute exacerbation of chronic obstructive pulmonary disease (AECOPD) especially for those requiring admission to an intensive care unit. Recognizing factors associated with mortality in these patients could reduce health care costs and improve end-of-life care.

Methods: This retrospective study included AECOPD patients admitted to the respiratory intensive care unit of a tertiary hospital in Beijing from Jan 1, 2011 to Dec 31, 2018. Patients demographic characteristics, blood test results and comorbidities were extracted from the electronic medical record system and compared between survivors and non-survivors.

Results: We finally enrolled 384 AECOPD patients: 44 (11.5\%) patients died in hospital and 340 (88.5\%) were discharged. The most common comorbidity was respiratory failure (294 (76.6\%)), followed by hypertension (214 (55.7\%)), coronary heart disease $(115$ (29.9\%)) and chronic heart failure (76 (19.8\%)). Multiple logistic regression analysis revealed that independent risk factors associated with in-hospital mortality included lymphocytopenia, leukopenia, chronic heart failure and requirement for invasive mechanical ventilation.

Conclusions: The in-hospital mortality of patients with acute COPD exacerbation requiring RICU admission is high. Lymphocytes $<0.8 \times 10^{9} / \mathrm{L}$, leukopenia, requirement for invasive mechanical ventilation, and chronic heart failure were identified as risk factors associated with increased mortality rates.
\end{abstract}

Keywords: Acute exacerbation of chronic obstructive pulmonary disease, In-hospital mortality, Predictors

\section{Introduction}

Chronic obstructive pulmonary disease (COPD) is a worldwide public health challenge because of high prevalence and related disability and mortality. World Health Organization projections predict that COPD-related mortality and disability will continue to increase worldwide until at least 2030 [1]. Acute exacerbation of COPD

\footnotetext{
*Correspondence: yanfeiguo2003@126.com

${ }^{\dagger}$ Yang Cao, Zhenzhen Xing, Huanyu Long and Yilin Huang contributed equally to this work

${ }^{4}$ National Clinical Research Center for Respiratory Diseases, Beijing, China

Full list of author information is available at the end of the article
}

(AECOPD), defined as the worsening of respiratory symptoms and requirement of additional clinical treatment, tends to be a critical factor leading to poor outcome [2]. Exacerbation of COPD reduces lung function and quality of life, and is accompanied by an increased disease-related burden and a high hospital mortality [24]. Several studies have identified factors independently associated with in-hospital mortality due to COPD exacerbations, including cardiac dysfunction, duration of hospital stay, older age, comorbidities and nutritional status, and arterial oxygen and carbon dioxide partial pressure at entry. However, independent prognostic factors differ between studies [5-8]. In addition, few studies original author(s) and the source, provide a link to the Creative Commons licence, and indicate if changes were made. The images or other third party material in this article are included in the article's Creative Commons licence, unless indicated otherwise in a credit line to the material. If material is not included in the article's Creative Commons licence and your intended use is not permitted by statutory regulation or exceeds the permitted use, you will need to obtain permission directly from the copyright holder. To view a copy of this licence, visit http://creativecommons.org/licenses/by/4.0/. The Creative Commons Public Domain Dedication waiver (http://creativeco mmons.org/publicdomain/zero/1.0/) applies to the data made available in this article, unless otherwise stated in a credit line to the data. 
specifically targeted patients admitted in respiratory intensive care unit (RICU). The purpose of our study was to determine hospital mortality rate and factors affecting mortality for patients with AECOPD requiring RICU admission.

\section{Methods}

\section{Study design and subjects}

The electronic medical records of all patients aged $\geq 40$ years admitted to the RICU with a diagnosis of AECOPD from Beijing Hospital during the period Jan 1, 2011 and Dec 31, 2018 were actively reviewed. AECOPD was defined as worsening of dyspnoea accompanied by increased cough and/or sputum volume or sputum purulence that results in additional therapy [2]. All diagnoses, including primary and five secondary diagnoses, were defined according to the International Classification of Diseases, 10th Revision (ICD10) coding system. Patients were excluded from the study if they were COPD patients admitted for diagnoses other than AECOPD. Patients whose duration of hospitalization was less than $24 \mathrm{~h}$, and those re-admitted within 1 month were also excluded. Laboratory results obtained within $24 \mathrm{~h}$ of admission were used in this study. The criteria for the management of AECOPD in the RICU did not change during the study period.

\section{Data collection}

Data were collected from the electronic medical record system, including demographic characteristics, routine blood tests, biochemical tests, arterial blood gases, pulmonary function tests and comorbidities. Demographic characteristic included age, gender, body mass index, smoking status, use of long-term home oxygen therapy, index of activities of daily living at admission, requirement for invasive mechanical ventilation and ventilator use duration. Blood tests included red cell count and white differential cell count, neutrophil-to-lymphocyte ratio, platelet-to-lymphocyte ratio, $\mathrm{C}$ reactive protein, $\mathrm{N}$-terminal pro-brain natriuretic peptide, $\mathrm{D}$-dimers, creatinine, uric acid. All blood samples were collected within $24 \mathrm{~h}$ after admission. Comorbidities recorded were: respiratory failure, hypertension, coronary heart disease (CHD) and chronic heart failure (CHF), atrial fibrillation, diabetes, and chronic kidney disease. Criteria for admission of AECOPD to the RICU did not change during the study period. The endpoint of the research was all-cause hospital mortality.

\section{Statistical analysis}

All data were analyzed by using SPSS 25.0 (IBM, NY, USA). Continuous variables were expressed as mean and standard deviation (SD). Clinical data are expressed as mean \pm SD for continuous variables then compared by $\mathrm{t}$-tests. Data for categorical variables were presented as counts and proportions, and were compared by $x^{2}$ tests. The collinearity was tested between variables and the variance inflation factor (VIF) was less than 10 indicating no collinearity between variables. Univariable and multivariable logistic regression analysis were used to explore the risk factors associated with in-hospital mortality for AECOPD. We also considered different cutoff values such as $p$-value $<0.25$, but gender and age were still not associated with in-hospital mortality as independent variables. Variables in univariate analyses with a p value $<0.1$ were finally included in the multivariable logistic regression analysis to identify the independent risk factors for in-hospital mortality. A p-value $<0.05$ was considered statistically significant.

\section{Results}

Between January 2011 and December 2018, 452 patients were admitted to the RICU for AECOPD. After excluding 4 patients with less than $24 \mathrm{~h}$ of hospitalization, 26 patients who were readmitted within one month and 38 patients with unavailable key data in the electronic medical record, we included 384 patients in the final analysis. Forty-four patients (11.5\%) died during their hospital stay, and 340 patients $(88.5 \%)$ were discharged.

\section{Clinical features and comorbidities in patients}

The present research included data of 384 AECOPD patients admitted to the RICU. Patients were divided into survivors and non-survivors based on in-hospital mortality. Demographic characteristics and baseline data of patients in the survival and non-survival groups are presented in Table 1 . The average age of all patients was $78.2 \pm 8.2$ years. There were more males (72.9\%) than females (27.1\%). Patients who died in the hospital had a lower ADL index at admission $(28.6 \pm 28.9)$ than survivors $(43.1 \pm 30.0, \mathrm{p}=0.003)$. The ventilation duration time was longer in non-survivors $(438.3 \pm 505.3 \mathrm{~h})$ than in survivors $(269.7 \pm 317.0 \mathrm{~h}, \mathrm{p}=0.042)$. Requirement for IMV was significantly higher in the non-survivor group $(65.9 \%$ vs. $7.1 \%, \mathrm{p}<0.001)$. The most common complication was respiratory failure (76.6\%), followed by hypertension, CHD and CHF. Patients with CHF as a comorbidity were more frequent in non-survivors than survivors $(50.0 \%$ vs. $15.9 \%, \mathrm{p}<0.001)$.

\section{Laboratory examination of patients on admission}

Table 2 shows laboratory results on admission. In non-survivors, mean leukocyte counts were higher $\left(10.2 \pm 6.3 \times 10^{9} / \mathrm{L}, \quad\right.$ vs. $\left.\quad 8.2 \pm 3.3 \times 10^{9} / \mathrm{L}, \quad \mathrm{p}=0.043\right)$, lymphocyte counts were lower $\left(0.84 \pm 0.89 \times 10^{9} / \mathrm{L}\right.$ vs $\left.1.09 \pm 0.60 \times 10^{9} / \mathrm{L}, \mathrm{p}=0.020\right)$, and less patients had 
Table 1 Clinical features and comorbidities in all patients included, in survivors and in non-survivors

\begin{tabular}{|c|c|c|c|c|}
\hline Variables & Total $(\mathrm{N}=384)$ & Survivors $(n=340)$ & Non-survivors $(n=44)$ & P value \\
\hline Age, years & $78.2(8.2)$ & $78.0(8.2)$ & $79.7(7.6)$ & 0.185 \\
\hline \multicolumn{5}{|l|}{ Gender } \\
\hline Male & $280(72.9 \%)$ & $244(71.8 \%)$ & $36(81.8 \%)$ & \multirow[t]{2}{*}{0.158} \\
\hline Female & $104(27.1 \%)$ & $96(28.2 \%)$ & $8(18.2 \%)$ & \\
\hline $\mathrm{BMI}, \mathrm{kg} / \mathrm{m}^{2}$ & $23.2(5.3)$ & $23.3(5.2)$ & $22.7(5.8)$ & 0.579 \\
\hline \multicolumn{5}{|l|}{ Smoking status } \\
\hline Never smoker & $85(22.3 \%)$ & $77(22.8 \%)$ & $8(18.2 \%)$ & \multirow[t]{3}{*}{0.073} \\
\hline Former smoker & $242(63.4 \%)$ & $208(61.5 \%)$ & $34(77.3 \%)$ & \\
\hline Current smoker & $55(14.4 \%)$ & $53(15.7 \%)$ & $2(4.5 \%)$ & \\
\hline Smoking exposure, pack-years & $35.6(34.5)$ & $35.3(35.0)$ & $38.3(30.8)$ & 0.593 \\
\hline Long-term home oxygen therapy & $76(19.8 \%)$ & $68(20.0 \%)$ & $8(18.2 \%)$ & 0.776 \\
\hline ADL index at admission & $41.3(30.2)$ & $43.1(30.0)$ & $28.6(28.9)$ & 0.003 \\
\hline Requirement for IMV & $53(13.8 \%)$ & $24(7.1 \%)$ & $29(65.9 \%)$ & $<0.001$ \\
\hline Ventilator use time, hours & $294.2(354.5)$ & $269.7(317.0)$ & $438.3(505.3)$ & 0.042 \\
\hline \multicolumn{5}{|l|}{ Comorbidities } \\
\hline Respiratory failure & $294(76.6 \%)$ & $258(75.9 \%)$ & $36(81.8 \%)$ & 0.382 \\
\hline Hypertension & $214(55.7 \%)$ & $194(57.1 \%)$ & $20(45.5 \%)$ & 0.145 \\
\hline $\mathrm{CHD}$ & $115(29.9 \%)$ & $102(30.0 \%)$ & $13(29.5 \%)$ & 0.951 \\
\hline CHF & $76(19.8 \%)$ & $54(15.9 \%)$ & $22(50.0 \%)$ & $<0.001$ \\
\hline Atrial fibrillation & $64(16.7 \%)$ & 55 (16.2\%) & $9(14.1 \%)$ & 0.474 \\
\hline Diabetes & $97(25.3 \%)$ & $85(25.0 \%)$ & $12(27.3 \%)$ & 0.744 \\
\hline CKD & $55(14.3 \%)$ & $47(13.8 \%)$ & $8(18.2 \%)$ & 0.437 \\
\hline
\end{tabular}

Date are presented as mean \pm standard deviation (SD) for continuous variables and percentages for categorical variables

$B M I$ body mass index, IMV invasive mechanical ventilation, CHF chronic heart failure, CHD coronary heart disease, CKD chronic kidney diseases

lymphocytopenia (lymphocytes $<0.8 \times 10^{9} / \mathrm{L}: 33.4 \%$ vs 65.9\%) than in survivors. NLR and PLR calculated from absolute numbers of lymphocytes, neutrophils and platelets (Table 2), were higher in non-survivors. CRP, NT-proBNP, and D-dimer were also significantly higher in non-survivors than in survivors. Conversely, albumin and $\mathrm{PaCO}_{2}$ were lower in non-survivors. No significant differences in lung function were noted.

\section{Independent risk factors for in-hospital mortality}

Requirement for IMV, the admission index of $\mathrm{ADL}$, CHF, WBC, lymphocyte, platelet, NLR, CRP, albumin, NT-proBNP, D-dimer and $\mathrm{PaCO}_{2}$ were all significant variables in univariable analysis (Table 3 ), while age, gender, smoking status and PLR were not included in the logistic regression analysis. This analysis showed that requirement for IMV (OR $=30.31,95 \%$ CI: 8.29110.74, $\mathrm{p}<0.001)$, CHF (OR = 7.63., 95\% CI: 2,27-25.64, $\mathrm{p}=0.001)$, leukopenia $(\mathrm{OR}=5.77,95 \% \mathrm{CI}: 1.05-31.74$, $\mathrm{p}<0.044)$ and lymphocytopenia $(\mathrm{OR}=3.60,95 \% \mathrm{CI}$ :
$1.10-11.76, \mathrm{p}=0.034)$ were independent risk factors associated with in-hospital mortality.

\section{Discussion}

The present study identified several risk factors for death in adults who were hospitalized with AECOPD in a respiratory ICU (RICU). In particular, lymphocytes $<0.8 \times 10^{9} / \mathrm{L}$, leukopenia, requirement for IMV, and having CHF were associated with higher odds of in-hospital death.

Knowledge about prognosis of disease and factors that predict poor outcome is important to help physicians to advise patients on the expected natural course of an illness. Several risk factors that predict death from AECOPD have been identified in prior studies. For instance, C-reactive protein (CRP), neutrophil-lymphocyte ratio (NLR), platelet-lymphocyte ratio (PLR), value of $\mathrm{D}$-dimers and $\mathrm{N}$-terminal-pro hormone $\mathrm{B}$-type natriuretic peptide (NT-pro BNP) have been reported as being associated with in-hospital mortality in AECOPD patients [9-14]. To the best of our knowledge, predicting 
Table 2 Laboratory results of patients within $24 \mathrm{~h}$ after admission

\begin{tabular}{|c|c|c|c|c|}
\hline Variables & $\begin{array}{l}\text { Total } \\
(\mathrm{N}=384)\end{array}$ & $\begin{array}{l}\text { Survivors } \\
(n=340)\end{array}$ & $\begin{array}{l}\text { Non-survivors } \\
(n=44)\end{array}$ & $P$ value \\
\hline White blood cell count, $\times 10^{9} / \mathrm{L}$ & $8.4(3.8)$ & $8.2(3.3)$ & $10.2(6.3)$ & 0.043 \\
\hline$<4$ & $21(5.5 \%)$ & $16(4.7 \%)$ & $5(11.4 \%)$ & 0.002 \\
\hline $4-10$ & $269(70.1 \%)$ & $248(72.9 \%)$ & $21(47.7 \%)$ & \\
\hline$>10$ & $94(24.5 \%)$ & $76(22.4 \%)$ & $18(40.9 \%)$ & \\
\hline Neutrophil count, $\times 10^{9} / \mathrm{L}$ & $7.3(7.8)$ & $7.1(8.0)$ & $8.8(6.4)$ & 0.187 \\
\hline Lymphocyte count, $\times 10^{9} / \mathrm{L}$ & $1.05(0.65)$ & $1.09(0.60)$ & $0.84(0.89)$ & 0.020 \\
\hline$<0.8$ & $141(37.2 \%)$ & $112(33.4 \%)$ & $29(65.9 \%)$ & $<0.001$ \\
\hline$\geq 0.8$ & $243(62.8 \%)$ & $228(66.6 \%)$ & $15(34.1 \%)$ & \\
\hline Platelet count, $\times 10^{9} / \mathrm{L}$ & $187.2(81.1)$ & $188.3(79.0)$ & $178.7(96.5)$ & 0.460 \\
\hline$<100$ & $40(10.4 \%)$ & $31(9.1 \%)$ & $9(20.5 \%)$ & 0.021 \\
\hline$\geq 100$ & $348(89.6 \%)$ & $309(90.9 \%)$ & $35(79.5 \%)$ & \\
\hline$N L R, \%$ & $10.8(17.3)$ & $9.6(16.7)$ & $19.9(19.5)$ & $<0.001$ \\
\hline$P L R, \%$ & $253.1(355.0)$ & $240.8(357.0)$ & $362.4(332.3)$ & 0.033 \\
\hline Eosinophil count, $\times 10^{9} / \mathrm{L}$ & $0.12(0.19)$ & $0.11(0.14)$ & $0.15(0.40)$ & 0.213 \\
\hline$C R P, \mathrm{mg} / \mathrm{L}$ & $5.1(7.0)$ & $4.7(6.7)$ & $8.4(8.6)$ & 0.002 \\
\hline Albumin, $\mathrm{g} / \mathrm{L}$ & $35.2(5.5)$ & $35.4(5.4)$ & $33.5(5.9)$ & 0.030 \\
\hline NT-proBNP, pg/ml & $1123.3(2586.0)$ & $948.0(2280.2)$ & $2474.3(4066.3)$ & 0.039 \\
\hline D-dimers, ug/L & $726.6(1075.8)$ & $676.5(1018.4)$ & $1127.0(1392.9)$ & 0.009 \\
\hline Creatinine, umol /L & $83.4(63.1)$ & $81.0(60.4)$ & $102.2(79.6)$ & 0.099 \\
\hline Uric acid, umol /L & $260.5(131.9)$ & $254.9(126.0)$ & $304.1(166.2)$ & 0.067 \\
\hline $\mathrm{pH}$ & $7.37(0.07)$ & $7.37(0.07)$ & $7.39(0.06)$ & 0.186 \\
\hline $\mathrm{PaO}_{2}, \mathrm{mmHg}$ & $78.0(25.9)$ & $77.9(23.2)$ & $78.3(41.4)$ & 0.960 \\
\hline $\mathrm{PaCO}_{2}, \mathrm{mmHg}$ & $52.8(15.8)$ & $53.5(16.1)$ & $47.7(12.5)$ & 0.022 \\
\hline $\mathrm{PaO}_{2} / \mathrm{FiO}_{2}, \mathrm{mmHg}$ & $275.7(85.5)$ & $277.59(83.9)$ & $260.7(96.7)$ & 0.225 \\
\hline Post-bronchodilator $\mathrm{FEV}_{1}^{*}, \mathrm{~L}$ & $0.94(0.46)$ & $0.95(0.46)$ & $0.82(0.10)$ & 0.705 \\
\hline Post-bronchodilator FVC ${ }^{*}, \mathrm{~L}$ & $1.95(0.69)$ & $1.95(0.70)$ & $1.77(0.42)$ & 0.714 \\
\hline Post-bronchodilator $\mathrm{FEV}_{1} / \mathrm{FVC}^{*}, \%$ & $47.16(12.39)$ & $47.13(12.39)$ & 48.61 (17.19) & 0.869 \\
\hline
\end{tabular}

Date is presented as mean \pm standard deviation for continuous variable and percentages for categorical variables

$N L R$ neutrophil/lymphocyte ratio, $P L R$ platet/lymphocyte ratio, CRP C reactive protein, NT-proBNP N-terminal pro-brain natriuretic peptide, FEV forced expiratory volume in $1 \mathrm{~s}, \mathrm{FVC}$ forced vital capacity, $\mathrm{PaO}_{2}$ arterial partial pressure of oxygen, $\mathrm{PaCO}_{2}$ arterial partial pressure of carbon dioxide

${ }^{*}$ Data missing for Post-bronchodilator $\mathrm{FEV}_{1}, \mathrm{FVC}$ and $\mathrm{FEV}_{1} / \mathrm{FVC}(\mathrm{n}=93)$

in-hospital mortality of ICU patients with AECOPD based on lymphocytopenia has been reported in only a few studies. Acanfora et al. showed that relative a lymphocyte count $\leq 20 \%$ was associated with higher risk of death in elderly patients with moderate-to-severe COPD [15]. Xiong et al. and Yao et al. noted that patients with COPD who died had a lower lymphocyte count than patients who survived, but lymphocyte count was not an independent risk factor for in-hospital mortality of AECOPD patients $[11,16]$. We observed that lymphocytopenia occurred in more than $65 \%$ of non-survivors and was an independent risk factor for in-hospital mortality (OR 3.60 (1.10-11.76)).

Mechanisms for lymphocytopenia predicting high risk of in-hospital death in patients with AECOPD remains unclear. Several facts should be considered. First, peripheral blood lymphocytes may be decreased in the elderly
$[17,18]$ and older age was also a significant risk factor for COPD mortality as reported in previous studies [19, 20]. Second, a lower lymphocyte count as a biomarker of inflammation could increase the risk of infection increasing risk of death from AECOPD. Lymphocytopenia was found in the critically ill patients with SARS$\mathrm{CoV}$ infection because targeted invasion by SARS-CoV viral particles damages the cytoplasmic component of the lymphocytes and causes their destruction [21]. Additionally, lymphocytopenia resulting from apoptosis of lymphocytes is also common in severe MERS infection [22]. In the present study, lymphocyte count was shown to be a useful, widely available, and inexpensive predictor that may help identify AECOPD patients admitted to the RICU at high risk of in-hospital mortality.

Requirement for IMV was a significant predictor of in-hospital mortality of AECOPD [20, 23]. In a study by 
Table 3 Logistic regression analysis of the in-hospital mortality of AECOPD requiring RICU admission

\begin{tabular}{|c|c|c|c|c|}
\hline Variable & Univariable OR $(95 \% \mathrm{Cl})$ & $P$ value & Multivariable OR $(95 \% \mathrm{Cl})$ & P value \\
\hline Age, years & $1.03(0.99-1.07)$ & 0.185 & & \\
\hline Gender (M/F) & $1.77(0.79-3.95)$ & 0.163 & & \\
\hline Requirement for IMV & $25.46(12.04-53.83)$ & $<0.001$ & 30.31 ( 8.29-110.74) & $<0.001$ \\
\hline The admission index of ADL & $0.98(0.97-1.00)$ & 0.004 & $0.99(0.97-1.02)$ & 0.578 \\
\hline Smoking status (ever vs. never) & $1.33(0.59-2.98)$ & 0.491 & & \\
\hline $\mathrm{CHF}$ & $5.30(2.74-10.23)$ & 0.001 & $7.63(2.27-25.64)$ & 0.001 \\
\hline \multicolumn{5}{|l|}{ White blood cell count, $\times 10^{9} / \mathrm{L}$} \\
\hline$<4$ & $3.95(1.31-11.94)$ & 0.015 & $5.77(1.05-31.74)$ & 0.044 \\
\hline $4-10$ & 1.00 (ref) & & 1.00 (ref) & \\
\hline$>10$ & $2.81(1.42-5.54)$ & 0.003 & $3.05(0.90-10.31)$ & 0.073 \\
\hline \multicolumn{5}{|l|}{ Lymphocyte count, $\times 10^{9} / \mathrm{L}$} \\
\hline$<0.8$ & $3.85(1.98-7.47)$ & $<0.001$ & $3.60(1.10-11.76)$ & 0.034 \\
\hline$\geq 0.8$ & 1.00 (ref) & & 1.00 (ref) & \\
\hline \multicolumn{5}{|l|}{ Platelet count, $\times 10^{9} / \mathrm{L}$} \\
\hline$<100$ & $2.56(1.23-5.82)$ & 0.025 & $1.64(0.30-8.91)$ & 0.652 \\
\hline$\geq 100$ & 1.00 (ref) & & 1.00 (ref) & \\
\hline$N L R, \%$ & $1.02(1.01-1.04)$ & 0.008 & $1.01(0.99-1.03)$ & 0.292 \\
\hline$P L R, \%$ & $1.00(1.00-1.00)$ & 0.115 & & \\
\hline \multicolumn{5}{|l|}{$C R P, \mathrm{mg} / \mathrm{L}$} \\
\hline$<10$ & 1.00 (ref) & & 1.00 (ref) & \\
\hline$\geq 10$ & $2.55(1.21-5.45)$ & 0.016 & $5.57(0.99-31.30)$ & 0.051 \\
\hline \multicolumn{5}{|l|}{ Albumin, g/L } \\
\hline$<35$ & $1.93(1.00-3.70)$ & 0.049 & $1.81(0.51-6.40)$ & 0.356 \\
\hline$\geq 35$ & 1.00 (ref) & & 1.00 (ref) & \\
\hline NT-pro BNP, pg/L & $1.00(1.00-1.00)$ & 0.014 & $1.00(1.00-1.00)$ & 0.163 \\
\hline \multicolumn{5}{|l|}{ D-dimer, ug/L } \\
\hline$<500$ & 1.00 (ref) & & 1.00 (ref) & \\
\hline 500-1000 & $2.08(0.98-4.42)$ & 0.057 & $1.07(0.26-4.33)$ & 0.931 \\
\hline$>1000$ & $2.97(1.33-6.63)$ & 0.008 & $1.97(0.44-8.65)$ & 0.369 \\
\hline $\mathrm{PaCO}_{2}, \mathrm{mmHg}$ & $0.97(0.95-1.00)$ & 0.026 & $0.99(0.94-1.05)$ & 0.508 \\
\hline
\end{tabular}

$I M V$ invasive mechanical ventilation, CHF chronic heart failure, NLR neutrophil/lymphocyte ratio, $P L R$ platet/lymphocyte ratio, NT-proBNP N-terminal probrain natriuretic peptide, CRP C reactive protein

Brown et al., 38.7\% of patients required IMV; multivariate analysis showed that requirement for IMV was strongly associated with in-hospital death [20]. Lindenauer PK et al. showed that in-hospital mortality was higher in COPD patients who required IMV than in patients with non-invasive ventilation (NIV) [24]. The results of the present study were consistent with previous studies. This finding is not surprising: typically, patients who require IMV rather than NIV are in a severe disease stage.

CHF is a common comorbidity of COPD [25]. In the present study, having CHF as a comorbidity was an important risk factor for predicting in-hospital mortality of AECOPD patients. Testa et al. found that patients with COPD and CHF had an increased risk of mortality compared with patients with either COPD or CHF alone [26]. The results of the present study were consistent with their study. There are some potential pathophysiological mechanisms that could explain the interaction between COPD and cardiovascular disease. With the progression of COPD, the increased pulmonary vascular resistance leads to pulmonary hypertension and right ventricular dysfunction. In addition, both hypoxia and acidosis can reduce diastolic and systolic myocardial dysfunction $[27$, 28].

Our study also has several limitations. Firstly, the results may not be generalizable to other ICU patients because of a single-center design. Secondly, management of respiratory insufficiency did not follow a prospective protocol and the individual preferences of the treating physician may have affected outcome. Thirdly, we do not have precise information on nutritional status or quality of life prior to admission. Fourthly, we had no detailed information about COPD severity (CAT, mMRC) because the included subjects are severe patients. And 
only 93 participants reported spirometry parameters owing to severe patients failure to cooperatively complete lung function test. Finally, the study could not provide post-hospital mortality data, which would be necessary for further validation of the prognostic factors in our findings.

Hospitalization for acute COPD exacerbation is becoming more frequent, and it places an enormous burden on patients and health care systems. In conclusion, the current study has identified a number of variables associated with in-hospital mortality for AECOPD patients in RICU.

\section{Acknowledgements}

Not applicable.

\section{Authors' contributions}

YFG and YC conceived and designed the study. YFG supervised the study. YC, ZZX and PZ did the statistical analysis. ZZX, JPJ and YFG reviewed and modified the manuscript. All authors contributed to acquisition, analysis, or interpretation of data. YFG, YC and ZZX drafted the manuscript. All authors revised the report and approved the final version before submission.

\section{Funding}

National Key R\&D Program of China (2018YFC1315101).

\section{Availability of data and materials}

The datasets during and/or analysed during the current study available from the corresponding author on reasonable request.

\section{Ethics approval and consent to participate}

Our study followed the Declaration of Helsinki and it was approved by the Ethics Committee of Beijing hospital (2019BJYYEC-018-02).

\section{Consent for publication}

Not applicable.

\section{Competing interests}

The authors declare that they have no competing interests.

\section{Author details}

${ }^{1}$ Department of Respiratory and Critical Care Medicine, Beijing Hospital, Beijing, China. ${ }^{2}$ National Center of Gerontology, Beijing, China. ${ }^{3}$ Institute of Geriatric Medicine, Chinese Academy of Medical Sciences, Beijing, China. ${ }^{4}$ National Clinical Research Center for Respiratory Diseases, Beijing, China.

${ }^{5}$ Department of Epidemiology, Institute of Geriatrics, Beijing Hospital, Beijing, China. ${ }^{6}$ Division of Pulmonary Diseases, Department of Medicine, Geneva University Hospitals, Geneva, Switzerland.

Received: 14 October 2020 Accepted: 8 February 2021

Published online: 04 March 2021

\section{References}

1. GBD 2015 Chronic Respiratory Disease Collaborators. Global,regional, and national deaths, prevalence, disability-adjusted lifeyears, and years lived with disability for chronic obstructivepulmonary disease and asthma, 1990-2015: a systematic analysis for the Global Burden of Disease Study 2015. Lancet Respir Med. 2017;5:691-706.

2. Singh D, Agusti A, Anzueto A, Barnes PJ, Bourbeau J, Celli BR, et al. Global strategy for the diagnosis, management, and prevention of chronic obstructive lung disease: the GOLD science committee report 2019. Eur Respir J. 2019;53(5):1900164.

3. Vogelmeier C, Criner G, Martinez F, Anzueto A, Barnes PJ, Bourbeau J, et al. Global strategy for the diagnosis, management, and prevention of chronic obstructive lung disease 2017 report. GOLD executive summary. Am J Respir Crit Care Med. 2017;195(5):557-82.

4. Kim V, Aaron SD. What is a COPD exacerbation? Current definitions, pitfalls, challenges and opportunities for improvement. Eur Respir J. 2018;52(5):1801261. https://doi.org/10.1183/13993003.01261-2018.

5. Ai Ping C, Lee KH, Lim TK. In-hospital and 5-year mortality of patients treated in the ICU for acute exacerbation of COPD: a retrospective study. Chest. 2005;128:518-24.

6. Rammaert B, Verdier N, Cavestri B, Nseir S. Procalcitonin as a prognostic factor in severe acute exacerbation of chronic obstructive pulmonary disease. Respirology. 2009;14:969-74.

7. Rivera-Fernandez R, Navarrete-Navarro P, Fernandez-Mondejar E, Rodriguez-Elvira M, Guerrero-López F, Vázquez-Mata G. Project for the Epidemiological Analysis of Critical Care Patients (PAEEC) Group. Six year mortality and quality of life in critically ill patients with chronic obstructive pulmonary disease. Crit Care Med. 2006:34:2317-24.

8. Ucgun I, Metinas M, Moral H, Alatas F, Yildirim H, Erginel S. Predictors of hospital outcome and intubation in COPD patients admitted to the respiratory ICU for acute hypercapnic respiratory failure. Respir Med. 2006;100:66-74.

9. Dahl M, Vestbo J, Lange P, Bojesen SE, Tybjaerg-Hansen A, Nordestgaard BG. C-reactive protein as a predictor of prognosis in chronic obstructive pulmonary disease. Am J Respir Crit Care Med. 2007;175(3):250-5.

10. Miniati M, Monti S, Bottai M, Cocci F, Fornai E, Lubrano V. Prognostic value of C-reactive protein in chronic obstructive pulmonary disease. Intern Emerg Med. 2011;6(5):423-30.

11. Yao C, Liu X, Tang Z. Prognostic role of neutrophil-lymphocyte ratio and platelet-lymphocyte ratio for hospital mortality in patients with AECOPD. Int J Chron Obstruct Pulmon Dis. 2017;12:2285-90.

12. Paliogiannis $P$, Fois $A G$, Sotgia S, Mangoni AA, Zinellu E, Pirina P, et al. Neutrophil to lymphocyte ratio and clinical outcomes in COPD: recent evidence and future perspectives. Eur Respir Rev. 2018;27(147):170113. https://doi.org/10.1183/16000617.0113-2017.

13. Hu G, Wu Y, Zhou Y, Wu Z, Wei L, Li Y, et al. Prognostic role of D-dimer for in-hospital and 1-year mortality in exacerbations of COPD. Int J Chron Obstruct Pulmon Dis. 2016;11:2729-36.

14. Hoiseth AD, Omland T, Hagve TA, Brekke PH, Soyseth V. NT-proBNP independently predicts long term mortality after acute exacerbation of COPD - a prospective cohort study. Respir Res. 2012;13(1):97. https://doi. org/10.1186/1465-9921-13-97.

15. Acanfora D, Scicchitano P, Carone M, Acanfora C, Piscosquito G, Maestri $\mathrm{R}$, et al. Relative lymphocyte count as an indicator of 3-year mortality in elderly people with severe COPD. BMC Pulm Med. 2018;18(1):116.

16. Xiong W, Xu M, Zhao Y, Wu X, Pudasaini B, Liu JM. Can we predict the prognosis of COPD with a routine blood test? Int J Chron Obstruct Pulmon Dis. 2017;12:615-25.

17. Rea IM, Stewart M, Campbell P, Alexander HD, Crockard AD, Morris TC. Changes in lymphocyte subsets, interleukin 2, and soluble interleukin 2 receptor in old and very old age. Gerontology. 1996;42(2):69-78.

18. Lehtonen L, Eskola J, Vainio O, Lehtonen A. Changes in lymphocyte subsets and immune competence in very advanced age. J Gerontol. 1990;45(3):M108-12.

19. Hartl S, Lopez-Campos JL, Pozo-Rodriguez F, Castro-Acosta A, Studnicka M, Kaiser B, et al. Risk of death and readmission of hospitaladmitted COPD exacerbations: European COPD Audit. Eur Respir J. 2016;47(1):113-21.

20. Brown H, Dodic S, Goh SS, Green C, Wang WC, Kaul S, et al. Factors associated with hospital mortality in critically ill patients with exacerbation of COPD. Int J Chron Obstruct Pulmon Dis. 2018;13:2361-6.

21. Yang $X, Y u Y, X u$ J, Shu H, Xia J, Liu H, et al. Clinical course and outcomes of critically ill patients with SARS-CoV-2 pneumonia in Wuhan, China: a single-centered, retrospective, observational study. Lancet Respir Med. 2020;8(5):475-81. https://doi.org/10.1016/S2213-2600(20)30079-5.

22. Chu H, Zhou J, Wong BH, Li C, Chan JF, Cheng ZS, et al. Middle East respiratory syndrome coronavirus efficiently infects human primary $T$ lymphocytes and activates the extrinsic and intrinsic apoptosis pathways. J Infect Dis. 2016;213(6):904-14.

23. Shi QF, Sheng Y, Zhu N, Tan Y, Xie XH, Wang SY, et al. The v-DECAF score can predict 90-day all-cause mortality in patients with COPD exacerbation requiring invasive mechanical ventilation. Clin Respir J. 2019;13(7):438-45 
24. Lindenauer PK, Stefan MS, Shieh MS, Pekow PS, Rothberg MB, Hill NS. Outcomes associated with invasive and noninvasive ventilation among patients hospitalized with exacerbations of chronic obstructive pulmonary disease. JAMA Intern Med. 2014;174(12):1982-93.

25. Griffo R, Spanevello A, Temporelli PL, Faggiano P, Carone M, Magni $\mathrm{G}$, et al. Frequent coexistence of chronic heart failure and chronic obstructive pulmonary disease in respiratory and cardiac outpatients: evidence from SUSPIRIUM, a multicentre Italian survey. Eur J Prev Cardiol. 2017;24(6):567-76.

26. Testa G, Cacciatore F, Bianco A, Della-Morte D, Mazzella F, Galizia G, et al. Chronic obstructive pulmonary disease and long-term mortality in elderly subjects with chronic heart failure. Aging Clin Exp Res. 2017;29(6):1157-64
27. Klinger JR, Hill NS. Right ventricular dysfunction in chronic obstructive pulmonary disease. Evaluation and management. Chest. 1991:99(3):715-23.

28. Shujaat A, Minkin R, Eden E. Pulmonary hypertension and chronic cor pulmonale in COPD. Int J Chron Obstruct Pulmon Dis. 2007;2(3):273-82.

\section{Publisher's Note}

Springer Nature remains neutral with regard to jurisdictional claims in published maps and institutional affiliations.
Ready to submit your research? Choose BMC and benefit from:

- fast, convenient online submission

- thorough peer review by experienced researchers in your field

- rapid publication on acceptance

- support for research data, including large and complex data types

- gold Open Access which fosters wider collaboration and increased citations

- maximum visibility for your research: over 100M website views per year

At BMC, research is always in progress.

Learn more biomedcentral.com/submissions 